\title{
Femur boyun kırıklarında kırık lokalizasyonunun instabilite ile ilişkisi: Biyomekanik çalışma
} Correlation between instability and fracture location in femur neck fracture: Biomechanical analysis

Yüksel Uğur Yaradılmış ${ }^{1}$ iD

Abdullah Eyidoğan ${ }^{3}$ D

Mustafa Caner Okkaoğlu² İsmail Demirkale ${ }^{2}$ D
Pınar Huri ${ }^{3}$ D

Murat Altay ${ }^{2}$ (D)

${ }^{1}$ Çankırı Devlet Hastanesi, Ortopedi ve Travmatoloji Bölümü, Çankırı, Türkiye

${ }^{2}$ Sağlık Bilimleri Üniversitesi Keçiören Eğitim ve Araştırma Hastanesi, Ortopedi ve Travmatoloji Kliniği, Ankara, Türkiye

${ }^{3}$ Ankara Üniversitesi Mühendislik Fakültesi Biyomedikal Mühendisliği Bölümü Ankara, Türkiye

Öz

Amaç: Femur boyun kırıklarında kırık konfigürasyonu ile instabilite arasında ilişki görülmekte iken kırık lokalizasyonu ile instabilite arasındaki ilişki literatürde yer bulmamıştıs. Çalışmamız femur boyun kırıklarında, kırığın femur boyun lokalizasyonu ile instabilite arasındaki ilişkiyi araştırdı.

Gereç ve Yöntem: Çalışmamızda 12 adet kompozit sentetik proksimal femur modeline üç farklı lokalizasyondan osteotomi yapıldı. Osteotomi lokalizasyonu; transservikal yerleşim (Grup 2), transservikal yerleşimin $5 \mathrm{~mm}$ proksimali (Grup 1=Subkapital), transservikal yerleşimin $5 \mathrm{~mm}$ distali (Grup 3=Bazoservikal) olmak üzere üç ayrı lokalizasyondan planlandı. Her femur modeli için Pauwels tip II osteotomi ve iki kanüllü vida ile tespit uygulanarak femur modelleri standardize edildi. Gruplara aksiyel yönde stres (kompresyon) uygulanarak stabilite, biyomekanik parametreler ile incelendi.

Bulgular: Stres/strain eğrileri gruplar içinde paralellik gösterdi ( $p>0,05)$. Gruplar arası değerlendirmede stres/strain eğrileri Grup 1'de yüksek gözlenirken, Grup 2 ve Grup 3'te eğrilerde paralel gözlendi. Sentetik kemik modellerinde strain değeri 4 olduğunda basınç ölçümleri; Grup 1'de $500 \pm 40 \mathrm{~N} / \mathrm{mm}^{2}$, Grup 2'de $370 \pm 36 \mathrm{~N} / \mathrm{mm}^{2}$, Grup 3'te $380 \pm 32 \mathrm{~N} / \mathrm{mm}^{2}(\mathrm{p}=0,000)$, strain değeri 6 olduğunda basınç ölçümleri; Grup 1'de $700 \pm 48 \mathrm{~N} / \mathrm{mm}^{2}$, Grup 2'de $520 \pm 50$ N/mm², Grup 3'te $510 \pm 53$ $\mathrm{N} / \mathrm{mm}^{2}$ olarak ölçüldü $(p=0,000)$. Grup 1 daha stabil gözlenirken, Grup 2 ile Grup 3 arasında fark gözlenmedi.

Sonuç: Femur boyun kırığı biyomekanik çalışmamızda transservikal ve bazoservikal bölge lokalizasyonlarında benzer stabilite gözlenirken, en proksimaldeki, subkapital bölge kırığının daha stabil olduğu gözlendi.

Anahtar Sözcükler: Femur boyun kırığı, lokalizasyon, instabilite, subkapital, biyomekanik analiz.

\section{Abstract}

Aim: Fracture configuration is associated with instability in femoral neck fractures but the effect of fracture localization on stability has not been reported in the literature. This study researched the relationship between femoral neck localization and instability in femoral neck fractures.

Materials and Methods: In this study, osteotomy was performed on 12 composite synthetic proximal femur models from 3 different locations. Osteotomy location; transcervical location (Group 2), $5 \mathrm{~mm}$ proximal of the transcervical location (Group 1=Subcapital), $5 \mathrm{~mm}$ distal of the transcervical location (Group 3=Basicervical). Each femur model was standardized by Pauwels Type II osteotomy and fixation with 2 cannulated screws. Stability was tested biomechanically by applying hydraulic press to the groups.

\footnotetext{
Sorumlu yazar: Yüksel Uğur YaradıImış

Çankırı Devlet Hastanesi, Ortopedi ve Travmatoloji Bölümü,

Çankırı, Türkiye

E-posta: ugur_yaradilmis@outlook.com

Başvuru Tarihi: 03.08.2019 Kabul Tarihi: 17.01.2020
} 
Results: Stress/strain curves were parallel in the groups $(p>0.05)$. While the stress/strain curves between the groups were high in Group 1, the curves in Group 2 and Group 3 were observed parallel. In synthetic bone models, the pressures measurements at strain level 4 were $500 \pm 40 \mathrm{~N} / \mathrm{mm}^{2}$ in Group $1,370 \pm 36 \mathrm{~N} / \mathrm{mm}^{2}$ in Group 2 and $380 \pm 32 \mathrm{~N} / \mathrm{mm}^{2}$ in Group $3(p=0.000)$. At strain level 6 the values were $700 \pm 48 \mathrm{~N} / \mathrm{mm}^{2}$ in Group $1.520 \pm 50 \mathrm{~N} / \mathrm{mm}^{2}$ in Group $2.510 \pm 53 \mathrm{~N} / \mathrm{mm}^{2}$ in Group 3 ( $p=0.000$ ). While Group 1 was more stable, there was no difference between Group 2 and Group 3.

Conclusion: In our biomechanical study of femoral neck fracture, similar stability was observed in the transcervical and basicervical localization, whereas proximal sub-capital fractures were more stable.

Keywords: Femur neck fracture, location, instability, subcapital, biomechanical analysis.

\section{Giriş}

Genç yaşlarda görülen femur boyun kırıklarında (FBK) fiksasyon ve osteosentez hedeflenmektedir (1). Femur boyun kırıklarında osteosentezin önündeki engeller ise femur boynunun beslenmesindeki kompleks yapı, intrakapsüler basınç ve yüksek yüklere maruz kalmasıdır (2). Femur boyun kırıklarında kaynama problemi yaşayan kırıklar incelendiğinde bazı kırık konfigürasyonları ön plana çıkmaktadır ki bunlar; deplase olan kırıklar (Garden 3, 4), dikey kırıklar (Pauwels III) ve subkapital kırıklar olarak sıralanabilmektedir (3).

Stabil olmayan kırıklar kaynamama probleminde risk faktörü olarak karşımıza çıkmaktadır. Pauwels ilk olarak 1935'te biyomekanik çalışmasında; femur boyun kırıklarını kırık çizgisinin yatay eğim derecesinde yönelimine göre sınıflandırmış ve dikey kırıklarda (Pauwels III) instabilite problemini göstermiştir (4). Son yıllarda ise biyomekanik çalışmaların kırık fiksasyon yöntemlerini geliştirmek ve fiksasyon kalitesini arttırmak üzere yoğunlaştığı görülmektedir. Kimi biyomekanik çalışmalar kanüllü vida tespit yöntemleri için vida konfigürasyonunu veya ek vida uygulamalarını araştırırken kimi biyomekanik çalışmalar ise daha invaziv fakat daha stabil tespit yöntemlerinin (dinamik kalça çivileri) üstünlüğünü göstermeye çalışmıştır (5-9). Stabil tedavi yöntemleri kadar instabil kırıkların da detaylı belirlenmesi prognoz tayini için önemlidir ki literatürde kırığın femur boynundaki yerleşiminin (lateralizasyonu veya medializasyonu) stabiliteye etkisi biyomekanik olarak araştırımamıştır.

Femur boyun kırıklarında prognoz tayini için Garden ve Pauwels sınıflamaları ön plana çıkmaktadır. Garden sınıflaması kırığın deplasmanına göre sınıflamasını belirlerken, Pauwels sınıflaması kırığın vertikal açısına göre kırıkları sınıflandırmıştır $(10,11)$. Kapsül içi kırık olan femur boyun kırıkları kırığın lokalizasyonuna göre ise transservikal, subkapital ve bazoservikal bölgede görülebilmektedir. Literatürde subkapital bölge kırıklarının kanlanma ve kaynama probleminden bahsedilmekte iken subkapital bölgedeki stabilite ile ilişkisi hakkında Pubmed'te sınır oranda yayın mevcuttur.

Bizim çalışmamızda femur boyun kırıklarında, kırığın femur boyun yerleşiminin stabiliteye etkisi biyomekanik olarak araştıııldı.

\section{Gereç ve Yöntem}

Çalışmamızda 12 adet kompozit sentetik proksimal femur modeli (3. kuşak kompozit proksimal femur, Selbones Araştırma Laboratuvarı, Kayseri, Türkiye), rastgele üç gruba ayrıldı. Femur boyunlarına üç farklı lokalizasyondan osteotomi planlandı. Osteotomi lokazisyonu; transervikal yerleşim (Grup 2), transervikal yerleşimin $5 \mathrm{~mm}$ proksimali (Grup $1=$ subkapital), transservikal yerleşimin $5 \mathrm{~mm}$ distali (Grup 3=bazoservikal) olmak üzere üç ayrı yerden yapıldı (Şekil-1). Osteotomi öncesi her femur modele iki adet Kirschner teli ile vida tespit yerleri belirlendi ve $6 \mathrm{~mm}$ dril ile delindi. Takiben daha önceden gruplara göre osteotomi yerleri belirlenen her femur modele Pauwel tip II osteotomi uygulandı. Osteotomi hattı redükte edilip (osteotomi öncesi femur boynuna redüksiyon belirlenmesi için uygulanan işaret yardımıyla) iki adet 7,3 yarım yivli kanüllü vida $(16 \mathrm{~mm})$ ile tespit edildi. Osteotomi ve tespitler tek ortopedi ve travmatoloji uzman doktoru tarafından, skopi kontrolünde yapıldı.

\section{Biyomekanik analiz}

Biyomekanik testler Ankara Üniversitesi Biyomedikal Mühendisliği Bölümünde dijital evrensel test sistemi (Shimadzu Corp. Japonya) kullanılarak yapıldı. Tüm femur modelleri koronal planda 25 derece adduksiyon, sagital pozisyonda nötral olmak üzere konumlandırıldı (Şekil-2). Gruplara aksiyel yönde stres (kompresyon) 
uygulanarak stabilite biyomekanik parametreler ile incelendi. Stres/strain eğrileri bilgisayar tabanlı veri toplama sistemi ile kaydedildi. Stres $\left(\mathrm{N} / \mathrm{mm}^{2}\right)$ ilişkili strain $(\mathrm{mm} / \mathrm{mm})$ değerleri sisteme kaydedildi. Gruplara arasında stres/strain eğrileri ve dayanım değerleri $\left(\mathrm{N} / \mathrm{mm}^{2}\right)$ karşılaştıııldı. Sentetik kemik kırıldığında veya 5 mm'den büyük bir kayma kırığı meydana geldiğinde başarısızlık olduğu kabul edildi.
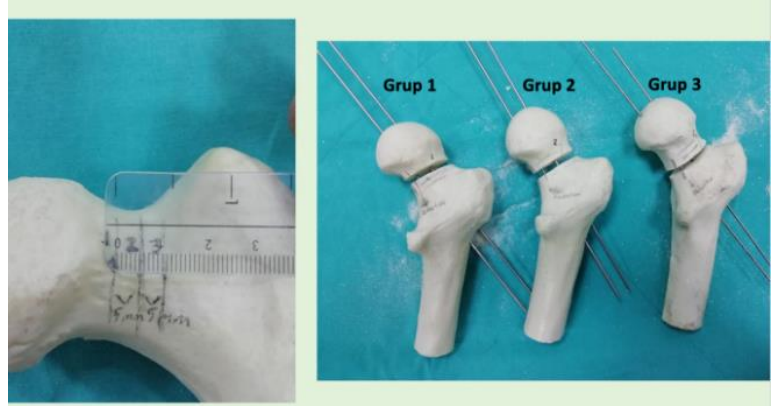

Şekil-1. Osteotomi lokalizasyonlarının belirlenmesi ve grupların oluşturulması; Grup 1: Transervikal yerleşimin $5 \mathrm{~mm}$ proksimali (subkapital), Grup 2: Transervikal yerleşim, Grup 3: Transservikal yerleşimin $5 \mathrm{~mm}$ distali (bazoservikal).

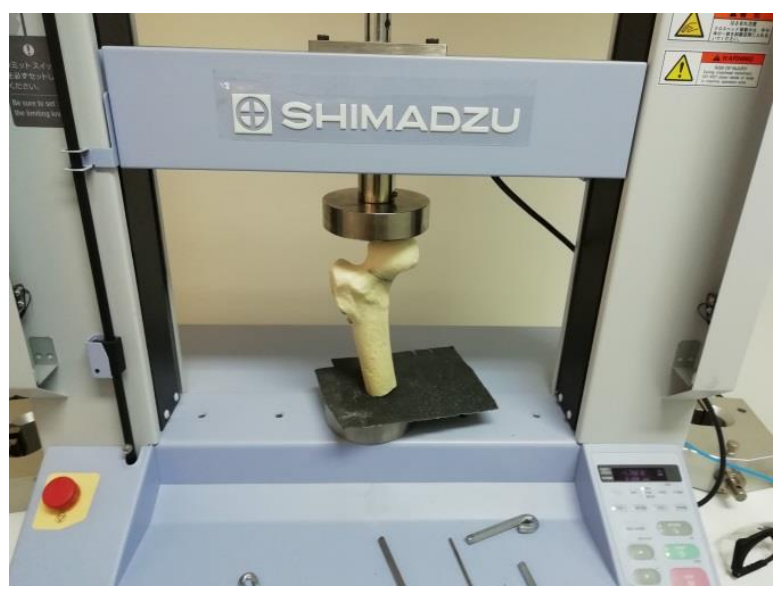

Şekil-2. Shimadzu Corp. (Japonya) modeli manuel dijital hidrolik pres cihazı ile aksiyel stres uygulanması ve femoral komponentlerin konumlandırılması (koronal planda 25 derece adduksiyon ve sagital pozisyonda nötral).

\section{Istatistiksel analiz}

Verilerin analizi SPSS 22 programı ile yapılmıştır. Verilerin normal dağılıma uygunluğu tek örnek Kolmogorov-Smirnov testi ile değerlendirildi. Sonuçlar ortalama \pm standart sapma (SS) olarak bildirildi. Gruplar tek yönlü varyans analizi kullanılarak değerlendirildi. Grupların stres/strain eğrileri tek yönlü Anova testi ile değerlendirildi. Gruplar arası ikili değerlendirmede Tukey testi uygulandı. Anlamlılık düzeyi $p<0,05$ olarak kabul edildi.

\section{Bulgular}

Stres/strain eğrileri gruplar içinde paralellik gösterdi $(p>0,05)$. Gruplar arası değerlendirmede stres/strain eğrileri Grup 1 de yüksek gözlenirken, Grup 2 ve Grup 3 de eğrilerde paralel gözlendi. Grupların ortalama stres/strain eğrileri Şekil-3'te sunuldu. Böylelikle, $5 \mathrm{~N} / \mathrm{mm}^{2}$ ön yük ile dakikada $10 \mathrm{~mm}$ kompresyon stresi oluşturulacak şekilde teste tabi tutulan sentetik kemik modellerinde strain değeri 4 olduğunda basınç ölçümleri; Grup 1 de $500 \pm 40$, Grup 2 de $370 \pm 36$, Grup 3 de $380 \pm 32 \mathrm{~N} / \mathrm{mm}^{2}(p=0,000)$, strain değeri 6 olduğunda basınç ölçümleri; Grup 1 de $700 \pm 48$, Grup 2 de $520 \pm 50$, Grup 3 de $510 \pm 53 \mathrm{~N} / \mathrm{mm}^{2}$ olarak ölçüldü $(p=0,000)$ (Tablo-1). Grup 1 daha stabil gözlenirken Grup 2 ile Grup 3 arasında fark gözlenmedi. Grupların ikili olarak incelemesinde Grup 2 ile Grup 3 arasında istatistiksel fark gözlenmedi ( $p=0,240, p=0,380)$.

Tablo-1. Gruplar için stres/strain değerleri.

\begin{tabular}{lllll}
\hline & \multicolumn{2}{l}{ Stres $\left(\mathbf{N} / \mathbf{m m}^{2}\right)$} & $\mathbf{p}$ \\
\hline Strain & Grup 1 & Grup 2 & Grup 3 & \\
2 & $250 \pm 18$ & $160 \pm 15$ & $200 \pm 20$ & 0,000 \\
4 & $500 \pm 40$ & $370 \pm 36$ & $380 \pm 32$ & 0,000 \\
6 & $700 \pm 48$ & $520 \pm 50$ & $510 \pm 53$ & 0,000 \\
\hline
\end{tabular}

\section{Tartışma}

Femur boyun kırıklarının komplikasyonları arasında osteonekroz (\%10-45) ve kaynamama (\%10-30) yüksek oranda görülmekte ve cerrahi sonrası takiplerde hep göz önünde bulundurulmaktadır. Her iki komplikasyonun da görülmemesi için anatomik redüksiyon ve stabil fiksasyon öncelikli şarttır $(12,13)$. Fiksasyon başarısızlığında ön plana çıkan nedenler instabil kırıklar ve fiksasyon tekniklerinin yetersiz kalmasıdır.

Stabil tespit için literatüre bakıldığında birçok biyomekanik çalışma karşımıza çıkmaktadır. Bu biyomekanik çalışmaların çoğu minimal invaziv tespit yöntemlerini geliştirmek üzeredir. Klinik çalışmalarda ise sıklıkla kullanılan kanüllü vida uygulamaları ve dinamik kalça çivisi uygulamaları ve bunların sonuçlarını görmekteyiz. Kanüllü vida tespiti için klasik görüş 135 derece açı ile üç vida tespitidir $(5,6)$. 


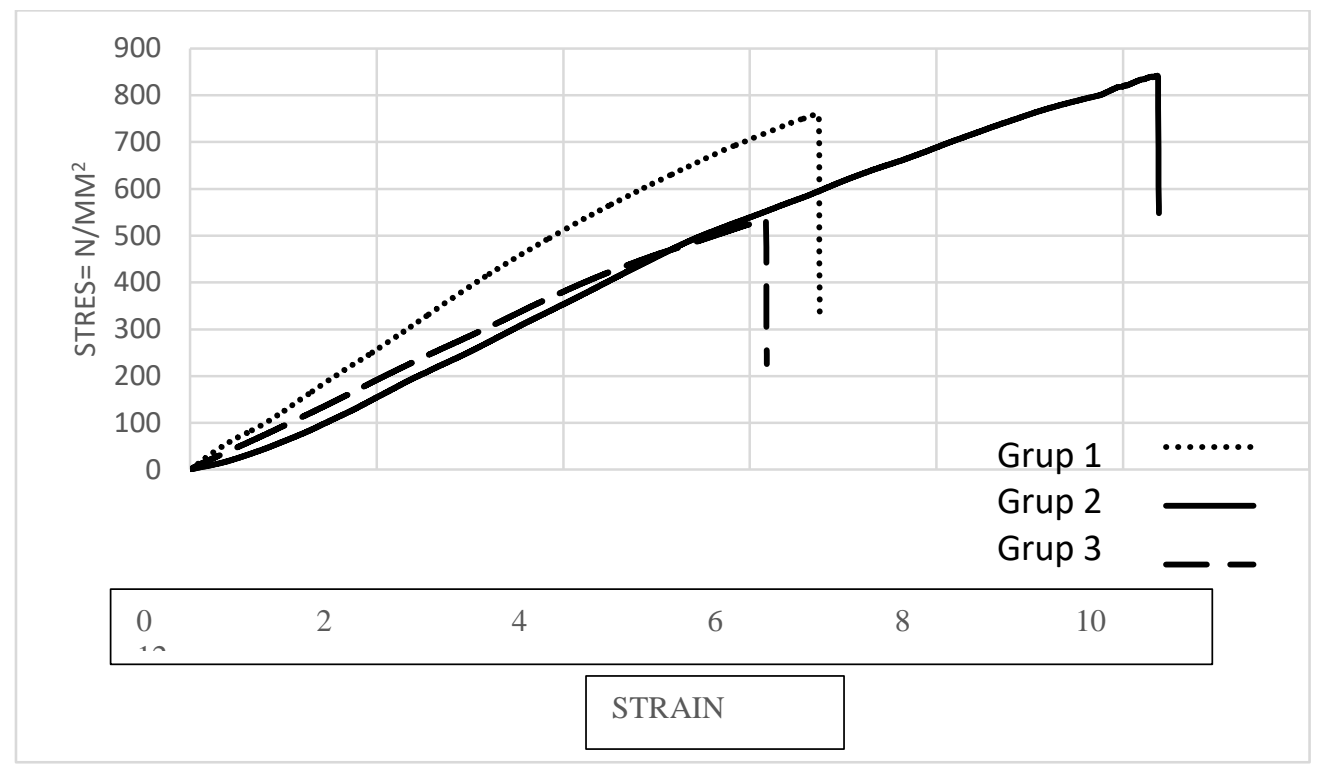

Şekil-3. Grupların stres-strain eğrileri.

Walker ve ark. biyomekanik çalışmalarında üç vidanın konfigürasyonlarını beş farklı konumlandırmayı incelemiş ve ters üçgen tespitinin daha stabil olduğunu gözlemişler (14). Pauwels tip III kırıklar için Gümüştaş ve ark. biyomekanik çalışmalarında ek dördüncü vida uygulamaları ve dördüncü vidanın farklı konumlandırılması ile daha güvenli bir fiksasyon sağlayabileceği gösterilmiştir (8). Yine biyomekanik çalışmalarda farklı bir fiksasyon yöntemi olan dinamik kalça çivisi (DHS) ile kanüllü vidalara göre yüksek stabilite elde edilmiş ve instabil kırıklar için önerilmiştir (9). Ma ve ark. klinik çalışmasında DHS ve kanüllü vida ile benzer fonksiyonel sonuçlar elde edilmesine rağmen DHS uygulanan hastalarda kaynama süresinin daha az bulunması ve komplikasyon oranındaki azalma dikkat çekmiştir (15).

Literatürde instabil femur boyun kırıkları olarak Garden 3,4 (deplase FBK) ve Pauwels tip 3 (vertikal FBK) kırıklar ön plana çıkmıştır. İnstabil femur boyun kırıklarını tanımlayan sınırlı sayıda biyomekanik çalışma vardır. Pauwels femur boyun kırıklarında instabilite ile kırık konfigürasyonunu incelemiş vertikal kırıklarda instabiliteye dikkat çekmiştir (4). Rivadeneira ve ark. femur boyun kırıklarında instabiliteye farklı bir açıdan değerlendirmiş; hastaların kemik mineralizasyon yoğunluğu (KMD) incelenmiş ve çalışmalarında düşük KMD değerlerinde oluşan kırıklarda instabiliteden bahsetmişlerdir (16). Proksimal femurda en büyük kemik desteği postero-medial korteks ile sağlanmaktadır. Bu sebeptendir ki posterior korteksteki parçalanma da femur boyun kırıklarında instabilite için bir etken olarak karşımıza çıkmaktadır. Literatürde kırığın femur boynundaki yerleşiminin stabiliteye etkisi biyomekanik olarak araştırılmamıştır.

Femur boyun kırıkları kapsül içi kırıklar olmakla birlikte; transservikal bölgede oluşabildiği gibi, daha proksimalde (subkapital bölge) veya daha distalde (bazosevikal bölge) de gözlenebilmektedir. Genç hastalarda tüm instabilite kriterlerine rağmen fiksasyon öncelikli tercihtir (1, 13). Bizim çalışmamızda femur boynunda yerleşimine göre kırık instabilitesi araştırıldı. Subkapital bölge kırıkları laterale göre daha stabil gözlenirken, transservikal ve bazoservikal bölgede de benzer stabilite gözlendi. Kalça biyomekaniği için bilinen kuvvet kolu ilişkisi nedeniyle kırığın medial yerleşimi daha stabil beklenmektedir (17, 18). Çalışmamızda da subkapital kırıklar için bu durum gözlendi. Osteotomi hattının lateralizasyon ile instabilite oluşmakla birlikte, transservikal ve bazoservikal bölgeler arasında biyomekanik olarak bu fark gözlenmedi.

Çalışmanın eksik yanlarından birisi sentetik komponentler arasında maksimum dayanım noktaları arasında tutarlılık gözlenmemiş olmasıdır. Biyomekanik çalışma ekibinden stresstrain eğrisinin stabilite hakkında yeterli bilgiyi verdiği görüşü alındı. Biyomekanik deneylerde aksiyel kompresif yüklenmeler uygulanırken 
döngüsel yüklenmelerin uygulanmaması çalışmanın diğer bir eksik yanı idi.

\section{Sonuç}

Femur boyun kırığı biyomekanik çalışmamızda transservikal ve bazoservikal bölge lokalizasyonlarında benzer stabilite özellikleri gözlenirken, daha medialdeki subkapital bölge lokalizasyonunda kırığın daha stabil olduğu daha gözlendi.

Çıkar çatışması: Yazarlar çıkar çatışması beyan etmemişlerdir.

\section{Kaynaklar}

1. Shah AK, Eissler J, Radomisli T. Algorithms for the treatment of femoral neck fractures. Clin Orthop 2002; 399: 28- 34.

2. Haidukewych GJ. Intracapsular hip fractures. Surgical treatment of orthopedic trauma, Stannard JP, Schmidt AH, Kregor PJ, Thieme New York, Stuttgart 2007; 539- 61.

3. Jo S, Lee SH, Lee HJ. The correlation between the fracture types and the complications after internal fixation of the femoral neck fractures. Hip \& pelvis, 2016; 28 (1): 35-42.

4. Bartonícek J. Pauwels' classification of femoral neck fractures: correct interpretation of the original. J Orthop Trauma 2001; 15: 358-60.

5. Sağlam N, Küçükdurmaz F, Kıvılcım H, Kurtulmuş T, Şen C, Akpınar F. Femur boyun kırıklarında üç kanüle vida ve minimal invazif antirotator kompresyon vidasının biyomekanik karşılaşıırması. Acta Orthop Traumatol Turc 2014; 48 (2): 196-201.

6. Walker E, Mukherjee DP, Ogden AL, Sadasivan KK, Albright JA. A biomechanical study of simulated femoral neck fracture fixation by cannulated screws: effects of placement angle and number of screws. Am J Orthop 2007; 36 (12): 680-4.

7. Mansur H, Alvarez R, Freitas A, Goncalves CB, Ramos MRF. Biomechanical analysis of femoral neck fracture fixation in synthetic bone. Acta ortopedica brasileira 2018; 26 (3): 162-5.

8. Gümüştaş SA, Tosun HB, Ağır İ, Orak MM, Onay T, Okçu G İnstabil femur boyun kıııklarının internal tespitinde vida sayısı ve yöneliminin stabiliteye etkisi. Acta Orthop Traumatol Turc 2014; 48 (6): 628-33.

9. Stoffel K, Zderic I, Gras F, Sommer C, Eberli U, Mueller D, Gueorguiev B Biomechanical evaluation of the femoral neck system in unstable Pauwels III femoral neck fractures: a comparison with the dynamic hip screw and cannulated screws. Journal of orthopaedic trauma 2017; 31 (3): 131-7.

10. Caviglia HA, Osorio $P Q$, Comando D. Classification and diagnosis of intracapsular fractures of the proximal femur. Clin Orthop 2002; 399: 17-27.

11. Pauwels F. Biomechanics of the normal and diseased hip. New York, Springer-Verlag, 1976; Chapter I; 1-21.

12. Freitas A, Torres GM, Souza ACAM, Maciel RA, Souto DRM, Ferreira GNB. Análise da resistência mecânica de fixação de fratura do colo femoral em osso sintético com DHS e parafuso antirrotatório. Rev Bras Ortop 2014; 49 (6): 586-92.

13. Leighton RK. Fractures of the neck of the femur. In: Bucholz RW, Heckman JD, Court-Brown CM, Ed, editors. Rockwood \& Green's fractures in adults. 6th. Lippincott Williams \& Wilkins; pp. 1780-1.

14. Li J, Wang M, Zhou J et. al. Optimum Configuration of Cannulated Compression Screws for the Fixation of Unstable Femoral Neck Fractures: Finite Element Analysis Evaluation. Biomed Research International 2018: Article ID 1271762. doi: 10.1155/2018/1271762.

15. Ma JX, Kuang MJ, Xing F et al. Sliding hip screw versus cannulated cancellous screws for fixation of femoral neck fracture in adults: a systematic review. International Journal of Surgery 2018; 52: 89-97.

16. Rivadeneira F, Zillikens MC, De Laet CE et al. Femoral neck BMD is a strong predictor of hip fracture susceptibility in elderly men and women because it detects cortical bone instability: the Rotterdam Study. Journal of Bone and Mineral Research 2007; 22 (11): 1781-90.

17. Turgut A. Kalça eklemi anatomisi ve biyomekaniği. TOTBID Dergisi 2015: 14: 27-33.

18. Nordin M, Frankel VH. Basic Biomechanics of the Musculoskeletal System 3rd ed. Baltimore: Lippincott Williams \& Wilkins; 2001: 203-5. 